\title{
Utilizando o software JCLIC enquanto tecnologia assistiva no tratamento do autismo
}

\section{Using the JClic software as assistive technology on treatment of autism}

\author{
Marcelo Teixeira, Anderson Santos, Cristiane Aquino, Edmar Medeiros \\ Universidade Federal Rural de Pernambuco
}

\begin{abstract}
Resumo
Como proposta para o presente estudo concebe-se o uso da ferramenta JClic para o desenvolver as habilidades da criança autista em cada necessidade específica, auxiliando no seu progresso educativo. $\mathrm{O}$ trabalho qualitativo e empírico descritivo, foi desenvolvido no Campus da Universidade Federal Rural de Pernambuco e na Escola Passo Dinâmico, no período de março de 2016 a março de 2017. Por fim, os resultados da pesquisa demonstram as potencialidades dos recursos tecnológicos enquanto tecnologias assistivas e de apoio didático para crianças com autismo de diferentes realidades sociais vivenciadas. Palavras chave: Tecnologia Assistiva, Jclic, Autismo.
\end{abstract}

\begin{abstract}
The proposed to the present study design is the use of the tool JClic to develop the autistic child's skills in each specific need assisting your educational progress. The study was carried out at the Campus of Federal Rural University of Pernambuco and Espaço Dinâmico School, from march 2016 to march 2017. Finally, the results of the research demonstrate the potential of technological resources as assistive technologies and didactic support for children with autism of different social realities. Keywords: Assistive Technology, Jclic, Autism.
\end{abstract}

\section{Introdução}

Novos modos de vida são permeados por uma cultura global que potencializa novas formas de sociabilidade no mundo contemporâneo através de tecnologias digitais. Em outras palavras, trata-se de uma virtualização cultural da realidade humana, fruto da migração do espaço físico para o virtual (mediado pelas tecnologias de informação e comunicação), regido por códigos, signos e relações sociais próprias. Avante, surgem formas instantâneas de comunicação, interação e possibilidade de rápido acesso às informações, no qual não somos meros emissores, mas produtores, reprodutores, colaboradores e distribuidores daquelas em diferentes campos do saber, incluindo as contribuições dos recursos tecnológicos para a saúde das pessoas, escreve Teixeira (2012) na obra "As faces da comunicação". Nesse contexto, o estudo em voga apresenta uma nova abordagem de atividades com uso do software JClic para educação especial, de acordo com as necessidades do Transtorno do Espetro Autista.

\begin{abstract}
Tecnologias Assistivas para o Autismo
$\mathrm{Na}$ vasta literatura sobre o tema, aprendemos que o transtorno do Autismo ou Transtorno do Espectro Autista se caracteriza pela presença do desenvolvimento prejudicado na interação social e comunicação, com prejuízos amplos em determinadas atitudes, como comportamentos não verbais (contato visual, gestos corporais, expressão facial) comprometendo e limitando o aprendizado. Estas características são manifestadas variando-se pelo desenvolvimento e idade da criança, costumando ser diagnosticada antes dos três anos de vida, explica Feedman (2008). Salvador (2016) adiciona que o autismo afeta direta e indiretamente a maneira como os indivíduos comem, vestem, trabalham, gastam o tempo de lazer, entendem o mundo, comunicam-se, etc. Deste modo, na opinião do autor, o autismo funciona como uma cultura em suas próprias características e modelos previsíveis de comportamento em indivíduos nessa condição.
\end{abstract}

Nesse sentido, historicamente, foi na década de 80 que o Transtorno do Espectro Autista começou a ser descrito no Manual de Transtornos Mentais (ou DSM), editado pela Associação Americana de Psiquiatria (em 1960), o qual tem expressiva importância nos parâmetros clínicos dos diagnósticos de transtornos neuropsiquiátricos em todos os continentes. No mais recente manual, o conceitua como um distúrbio de desenvolvimento que leva a severos comprometimentos de comunicação social, comportamentos restritivos e repetitivos que tipicamente se iniciam nos primeiros anos de vida do ser humano. Em contexto educacional, grande parte dos educadores de autistas são como intérpretes interculturais, alguém que entende ambas culturas e está apto para traduzir as expectativas e procedimentos do ambiente não autista para o aluno com autismo. Sobre o assunto, as pesquisas de Nilton Salvador (2016) revela que aproximadamente $10 \%$ a $15 \%$ dos indivíduos com autismo têm inteligência normal ou ou acima do normal (incluindo aqueles que possuem QIs acima acima da media); $25 \%$ a $35 \%$ estão numa média à beira de um suave retardo mental, enquanto os outros são, moderada ou profundamente retardados. Na prática, a média de QIs encontrada em pessoas com autismo têm grande variação, bem como a 
disseminação das habilidades de cada indivíduo (ibidem). De fato, considerando o processo educativo, o transtorno é de difícil tratamento e utilização de metodologias de aprendizagem que se adéquem as necessidades de aprendizagem da criança. Entre os quais, destacam-se: Distúrbios da percepção e imaginação em diferentes situações para a idade; Distúrbios do relacionamento; Sorrisos inapropriados (sem motivos aparentes); Reduzido ou nenhum contato visual; Preferência pela solidão e isolamento; Distúrbios de motilidade; Fixação em objetos de forma inapropriada; Hiperatividade ou inatividade extrema; Perseverança pela repetição de movimentos e palavras; Resistência à mudança de rotinas; Ausência de medo ao perigo real; Distúrbios da fala e da linguagem; entre outros. Entre os métodos utilizados para amenizar as incapacidades geradas pelo transtorno, se evidencia o Método TEACCH (Treatment and Education of Autistic and Related Communication Handicapped Children) - Tratamento e Educação para Crianças Autistas e Deficiências Relacionadas à Comunicação.

Criado nos anos 60 na Universidade da Carolina do Norte (EUA) por Eric Shopler, o Método TEACCH advoga que o autismo pode ser melhor compreendido como um transtorno invasivo do desenvolvimento humano e que a criança com esse problema evoluirá positivamente com um tratamento que combina a terapia comportamental e a educação especial. Ou seja, trata-se de um método psicoeducacional que assegura que tais crianças respondem melhor a realidades estruturadas de acordo com suas limitações e potencialidades. Daí, suas envolvem, essencialmente, a estruturação do ambiente, a utilização de tarefas adaptadas e a programação da rotina da criança com autismo, afirmam De Leon e Osório (2011) citados em Santos et al. (2013). Aliado ao Método TEACCH, o uso de tecnologias assistivas, conforme os autores têm sido disseminados no processo de educação de alunos com necessidades especiais, fornecendo um suporte de apoio ao processo de ensino aprendizado, proporcionando incremento qualitativo e/ou quantitativo nas atividades funcionais. A proposta da tecnologia assistiva (como o software JClic) é tornar atividades simples em prováveis, englobando inúmeros papéis desde afazeres básicos até as atividades de lazer e trabalho. Ademais, tornar possível que os educadores desenvolvam jogos e criem atividades educativas para diferentes propósitos de aprendizagem. Aqui, muito claramente se alinha como a Teoria Behaviorista. Por outro lado, proporciona a colaboração entre instituições de ensino e a troca de saberes para com os materiais didáticos utilizados.

Desenvolvido nos anos 2000 por Francesc Busquets, o software educativo multimídia e de autoria JClic (baseado em jogos e em padrões abertos para a utilização em qualquer sistema operacional), é composto por um leque de atividades educativas para serem utilizadas dentro e fora do ambiente escolar, como: • Associações - pretendem que o usuário descubra as relações existentes entre dois conjuntos de informação. • Jogos de memória - onde temos que descobrir pares de elementos iguais ou relacionados entre si que estão escondidos. - Explorador, Identificando células e Tela de informação - que partem de um único conjunto de informação. - Quebra-cabeças (puzzle) - planeja a reconstrução de uma informação que está inicialmente desordenada. - Atividades de resposta escrita - são resolvidas escrevendo-se um texto (uma só palavra ou frases relativamente complexas). - Texto: atividades de texto - são planejados exercícios baseados sempre nas palavras, frases, letras e parágrafos de um texto. Estes podem conter também janela de imagem com conteúdo ativo. - Cata-palavras e Palavras cruzadas - são variantes interativas dos conhecidos passatempos com palavras escondidas (SEED, 2010). Assim, as atividades são agrupadas em projetos personalizados e individuais, incluindo atividades e sequências ordenadas (semelhante a linguagem "LOGO" desenvolvida por Papert na década de 60). Para tanto, se faz necessário realizar o download do software no computador/tablet do usuário. $\mathrm{O}$ software possibilita usar recursos multimídia e armazenar os conteúdos em nuvem, podendo ser utilizado em qualquer espaço e tempo. Além disso, tem uma interface gráfica intuitiva e que estimula a curiosidade da criança.

\section{Método}

O presente estudo está norteado por uma metodologia qualitativa de cariz empírico descritivo. Nesse contexto, para conceber esse trabalho, realizamos uma revisão da literatura utilizando bibliotecas e repositórios virtuais da IEEE, ACM, RepositoriUM (Universidade do Minho) sobre o tema, de 2007 a 2017, no período de março de 2016 a março de 2017, e descobrimos alguns estudos que indicam a eficácia de utilização do Software JCLIC com o Tratamento e Educação para Crianças Autistas e Deficiências Relacionadas à Comunicação. Ainda, se descreve o Estudo de Caso da Escola Passo Dinâmico ao utilizar o JClic. Face a tais contribuições, assim sendo, o objetivo fulcral é destacar a próspera relação entre uma tecnologia assistiva recorrente na literatura e um método eficaz de tratamento para portadores de autismo.

\section{Resultados}

As plataformas de e-learning incorporam uma grande variedade de recursos e aplicativos da Web que servem de apoio didático ao processo educativo online. Constantemente aprimoradas pelo desenvolvimento tecnológico, adaptam-se ao mercado educacional de elearning consoante as exigências dos utilizadores e das comunidades a qual fazem parte. 
A título de exemplo, apresentamos o website da plataforma PRAL pela oferta diversificada e "customizada" de interfaces no ambiente virtual de aprendizagem:

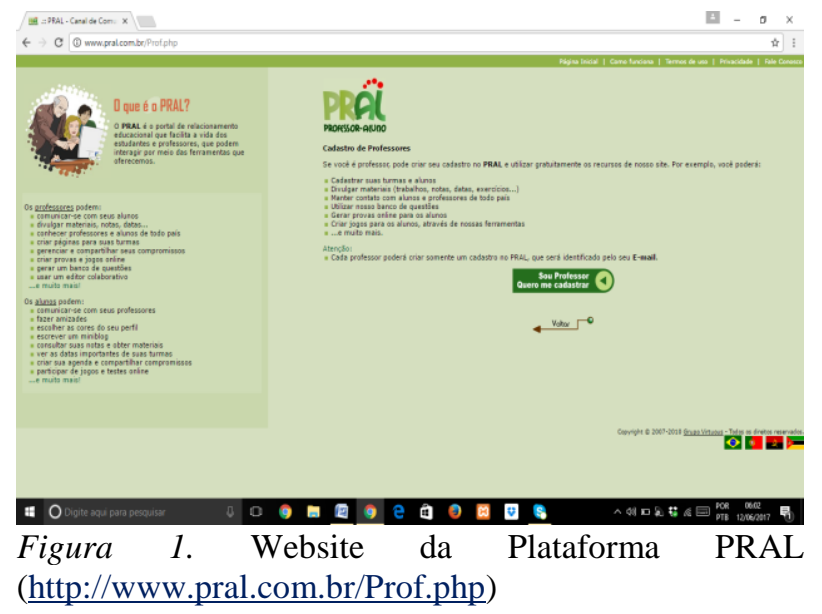

Audacity, chat, message, e-mail, blog, fórum de discurssão, newsletter, twitter, podcast, vodcast, youtube, newsgroup, feed RSS, facebook, flickr, wiki e, entre outras interfaces, o Jclic. São frequentemente encontradas nesses ambientes virtuais de aprendizagem.

A Virtuous Tecnologia Educacional deu origem a plataforma de aprendizagem e foi pioneira ao criar o primeiro portal de relacionamento educacional da Web a PRAL (www.pral.com.br), em 2005. Atualmente utilizado por mais de 30 mil professores para comunicação com seus alunos dentro e fora do Brasil, a PRAL (Portal de Relacionamento Professor-Aluno) é um ambiente educacional moderno e dinâmico, pois possibilita um cenário virtual de interação entre professores e alunos, que por sua vez oferece ferramentas educacionais distintas para ambos.

Deste modo, possibilita uma educação mais colaborativa e participativa para o processo de ensino e aprendizagem. Nessa estrutura, alunos, professores e a escola são possibilitados tornam a aprendizagem um processo contínuo que vai além dos muros da instituição de ensino. Os educadores podem comunicar-se com seus alunos, divulgar materiais, notas e datas, conhecer professores e alunos de todo país, criar páginas para suas turmas, elaborar provas e jogos on-line (Teixeira, 2013).

Além de "open source", seu ambiente de aprendizagem atrai cada vez mais educadores em países lusófonos, principalmente, em países como Moçambique, Cabo Verde, Brasil e Portugal, pela simplicidade de uso das interfaces multimídia que norteia as atividades propostas no processo educativo.

Com base nessas potencialidades, a Escola Espaço Dinâmico, Localizada em Pernambuco (Brasil), que atende a crianças e adolescentes do ensino fundamental ao médio (algumas com diferentes graus de autismo) decidisse inserir um link entre a Plataforma Pral (utilizada nas disciplinas de informática) e o software JClic (www.jclic.br.uptodown.com/windows/download) visando uma maior integração dos estudantes num ambiente de aprendizagem não apenas nas aulas de computação. Ou seja, a ideia é estimular a resolução de questões em grupo e fazer com que a comunidade estudantil se envolva numa atividade educativa extra curricular e no relacionamento entre os colegas de classe, tudo acompanhado, além do professor, por uma pedagoga, especialmente voltada às crianças com leve grau autismo (grau 1).

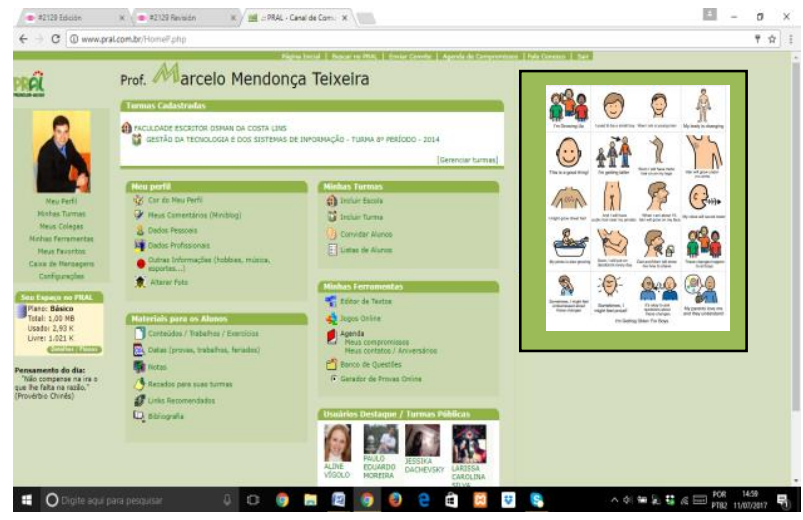

Figura 2. Website da Plataforma PRAL (Ambiente de Atividades) (http://www.pral.com.br/Prof.php)

Criação de jogos de memória, quebra-cabeças, caçapalavras, forca, são algumas atividades do software JClic ao qual podem ser utilizadas dentro do ambiente virtual de aprendizagem, neste caso, na Plataforma Pral. Abaixo, destacamos o ambiente onde o professor indica as atividades para a comunidade estudantil (figura 3.) e como se apresenta no ambiente virtual de aprendizagem (figura 4):

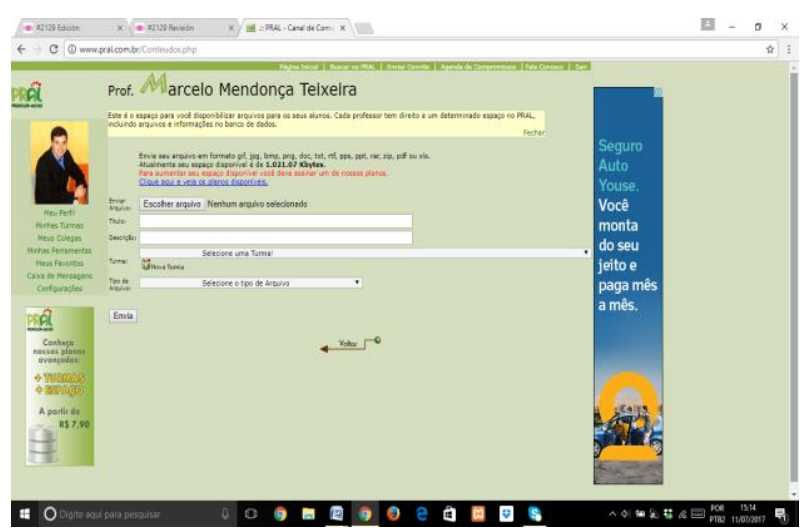

Figura 3. Website da Plataforma PRAL (Ambiente de Atividades) (http://www.pral.com.br/Prof.php)

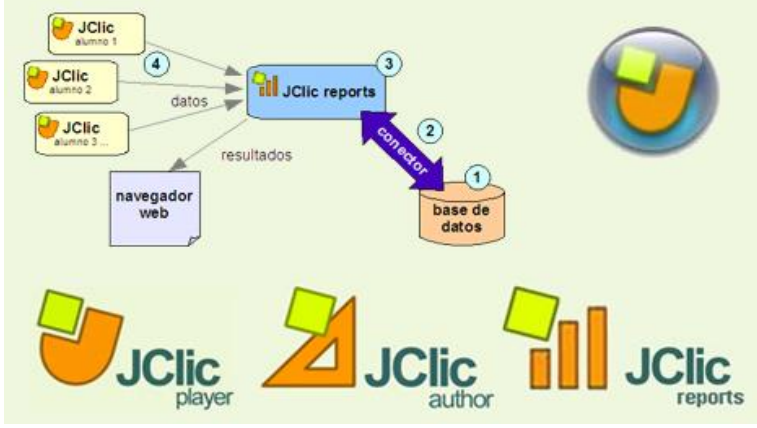

Figura 4. JClic integrado a um AVA (http://stellae.usc.es/red/blog/view/31598/jclic) 
Segundo a Diretora Tereza Campos de Oliveira, a experiência foi excelente em turmas do ensino médio (participaram 21 alunos) porque promoveu a interatividade e a construção coletiva do conhecimento (jogo quiz), mas com certa dificuldade para a resolução das questões propostas pelo educador com as turmas do ensino fundamental (participaram quatro alunos), mas com evidente estímulo ao desenvolvimento cognitivo do aluno (associação entre imagens e palavras). De acordo com ela, são duas motivações em voga: uma é a falta de preparo do professor em criar as atividades correspondes aos seus objetivos de aprendizagem, e, por consequência, o outro é desenvolver um ambiente adequado a diferentes níveis de aprendizagem dos alunos.

\section{Conclusão}

Através do estudo realizado, destacamos algumas potencialidades de utilização de uma tecnologia assistiva baseada em jogos (como o JClic) atuando em conjunto com o Método TEACCH, voltado ao tratamento e educação para crianças autistas e deficiências relacionadas à comunicação. Nesse sentido, trata-se de mais uma contribuição acerca de recursos tecnológicos que podem ser eficazmente usados no processo de ensino e aprendizagem por educadores do ensino fundamental e médio e que trazem reais melhorias para o quadro clínico da criança que sofre da patologia, já que não existe cura para o autismo, apenas tratamentos específicos que venham amenizar o quadro da doença, especialmente quanto a comprometimento da interação social, comunicação verbal e não verbal, e comportamento restrito e repetitivo.

Noutro sentido, em meio as inúmeras capacidades e funcionalidades educomunicativas das plataformas de aprendizagem e de softwares educacionais como o JClic, o inerente desafio aos educadores é saber como usar os recursos e adaptá-los as necessidades de aprendizagem dos educandos. Quando reconhece que as interfaces requerem cuidado e precisam ser preparadas para uma tarefa. Acima de tudo, necessitam do elemento humano para funcionar, afirmam Aquino e Teixeira (2015). Da mesma forma, é necessário um bom planejamento dos cenários pedagógicos. Não se pode simplesmente transferir os métodos da educação presencial, é preciso verificar necessidades, conhecer o potencial das interfaces e descobrir novos horizontes de aplicação. As pessoas utilizarão os novos recursos quando enxergarem sentido e quando forem motivadas para tal. Essa tem sido uma preocupação constante entre as empresas de e-learning em busca de fidelizar um público exigente na qualidade de ensino. Portanto, com base neste estudo incipiente e em contínua evolução, constatamos que a muito a ser feito em relação ao uso das interfaces didáticas em plataformas de aprendizagem. Por fim, a pesquisa realizada se caracteriza como uma nova fonte bibliográfica sobre o a utilização do software JClic.
Agradecimentos

Grupo de Pesquisa Tecnologias Colaborativas em Saúde (TECNES) - Universidade Federal Rural de Pernambuco.

\section{Referencias}

Aquino, C. D.; Teixeira, M. M. (2015). Comunicação midiática, hipertexto e interação. Raleigh: Lulu Publish.

Feedman, J. (2008). Autism. New York: Rosen Publishing.

Salvador, N. (2016). Autismo: deslisando nas ondas. Porto Alegre: Age Editora.

Santos, M. V. P. dos, Cunha, M. X. C. da, Medeiros, L. M., Maia Júnior, R. M. \& Bessa, B. R. (2013). Proposta de jogo usando tecnologias assistivas para auxílio na rotina diária de crianças autistas. Palmas: 2012, VII CONNEPI, pp. 4-8.

Seed (2010). Softwares livres educacionais. Brasilia: Ministério da Educação.

Teixeira, M. M. (2013). Da educação a distância às plataformas de e-learning: sistemas alternativos de educação mediada. Munique: Grin Verlag.

Teixeira, M. M. (2012). As faces da comunicação. Munique: Grin Verlag. 